THE BRITISH JOURNAL OF VENEREAL DISEASES

\title{
TUBERCULOSIS, VENEREAL DISEASES AND THE PUBLIC*
}

\author{
RADIO BROADCAST by SIR WILSON JAMESON, M.A., M.D., F.R.C.P., \\ LL.D., D.P.H. \\ Chief Medical Officer, the Ministry of Health
}

\section{Introduction}

The first radio broadcast on health matters to the general public introducing the subject of venereal diseases was delivered by Sir Wilson Jameson on October 23rd, 1942. This forward step in the policy of enlightenment of the public and in soliciting their cooperation is an outstanding event in the history of the venereal diseases campaign and of broadcasting in Great Britain.

The judiciously proportioned treatment of venereal diseases and of tuberculosis as infectious diseases of increasing importance in war-time was a most skilful introduction of a subject in which enlightenment of the people has been hampered for many years by traditional barriers of silence. The broadcast, which is a masterpiece in simplicity, is an innovation in the campaign of bringing to light in its proper role what has remained for so long a hidden subject. The restrained simplicity with which the two subjects were treated was an excellent first radio approach to a war-time public whose receptivity and responsiveness has greatly increased since the outbreak of war.

The broadcast is reproduced here on request for those readers of the Journal who unfortunately failed to hear Sir Wilson Jameson's talk in October last.

\section{The broadcast}

"From time to time during the past two years I have been privileged to tell the British public that our health during the war years has been remarkably good. We have escaped any serious epidemic, we are still well nourished and, in spite of all we have endured, we have lots of work-yes, and lots of fight-in us still.

" It is part of the policy of the Ministry of Health to take the public into its confidence in all matters affecting health, and tonight I want to talk to you for a few minutes about two diseases which, although they showed a steady decline before the war, have unfortunately increased since 1938. This increase was to some extent foreseen because these two diseases seem to thrive on the conditions brought about by war. There is nothing to be alarmed about, but it would be foolish of me to pretend that everything is just as it should be, when in fact it isn't-and the two black spots are tuberculosis and venereal disease.

"And first of all tuberculosis-called consumption when it affects the lungs. I can well remember how everybody used to be afraid of it. Indeed in the old days it was known as the 'White Plague' and the 'Captain of the Men of Death.' Well, much of that fear has gone now. The public have learned a lot about consumption. It has been discussed quite openly and everybody understands that if we can detect the disease in its early stages we have every prospect of curing the patient and restoring him once more to full working capacity-but we must discover the signs of the disease before they have become advanced.

"To show you how much tuberculosis has declined let me tell you that the number of deaths was just about halved in the thirty years.

"Now the distressing part of the story is that during the war years (just as in the last war) the number of deaths and the number of new cases have risen-not a great deal, but quite enough to cause us some anxiety. In 1941 deaths from tuberculosis showed a 13 per cent increase over the number in 1938-9. This rise is probably due to all the worries and discomforts of war-time-the black-out, the long hours of work, the difficulties of travel, anxiety about absent relatives and friends, the transfer of more or less susceptible people to war work of various kinds.

*Radio Broadcast made October 23rd, 1942. 


\section{RADIO BROADCAST}

"It is difficult to deal adequately with these circumstances. Tuberculosis can be prevented only by improving conditions of living, and of working and by providing the right foods in the right amounts-especially safe milk-that's to say milk that has been properly pasteurized or so treated by heat that all disease germs are destroyed. Remember that tuberculosis is an infectious disease-it is contracted either from a person suffering from consumption or through drinking milk from an infected cow.

"To make real progress in the prevention of tuberculosis in war-time is not easy, but we must do what we can. Another method of attacking the disease, however, is to adopt better methods of detection so that we can discover the disease in its earliest stages and then to see that these early cases are given proper treatment and care.

"Early detection has been helped in recent years by the introduction of a new type of X-ray machine which takes X-ray photographs of the chest on a strip of cinema film. With the help of this machine we can examine large numbers of people in a comparatively short time and at a much lower cost than if we used the full-sized X-ray apparatus. By this method we're enabled to sort out large groups of people and to decide which of them should be sent on for a more detailed investigation.

"This is very important for it must be realized that people who have got some infection with the germs of tuberculosis may not feel ill at all or show any signs when a doctor makes an examination of the chest. Indeed most of us recover naturally from such minor infections, though some of us don't without undergoing a period of treatment.

"We want in the course of time to make this new form of X-ray examination part and parcel of any ordinary medical inspection-just like counting the pulse or looking at the tongue. It's only in this way that we shall find out which of us may require more care and attention if we are to strengthen our natural defences against this insidious disease.

"You may have heard a few days ago that the Minister of Health has arranged for a number of these special X-ray machines to be manufactured, and we hope before long to begin this sort of examination of some of the most susceptible age groups-especially those between say seventeen and twenty-five or thirtyyoungsters leaving school, others working in offices or factories. In all three fighting Services this method has been adopted and we want the civil population to have the same benefits as the Services-whenever we can.

" Those who are found to need treatment must be given the chance of going to a hospital or a sanatorium if such a course is thought advisable, and the Government has decided to make a contribution towards the cost incurred by any wage-earner with dependents of keeping his home together while he is undergoing treatment. We are providing enough hospital accommodation and, of course, there must be sufficient nurses and domestic staff to enable the accommodation to be used.

"We've got to tackle this problem of tuberculosis-haven't we ? We can do a lot even in war-time. Indeed, it's the war that has made obvious the need to start a fresh attack on the disease. But in this matter doctors must have the cooperation of the public-we can do little without the support of well informed public opinion.

"And now for a few words about venereal disease, the two chief forms of which are syphilis and gonorrhoea. Both these diseases are caused by germs which live in the human body and die very rapidly outside the body. They're contracted in the main as a result of irregular sexual relationships, but there's a large amount of such disease contracted quite innocently. Thus an infected man may give the disease to his wife and she in her turn may transmit the infection to her unborn baby. The after-effects of these diseases, if they go untreated, may be terrible. Babies born dead, children becoming blind, women unable to bear children, men and women suffering and dying from certain diseases of the brain and heart. It's the late, often very late, manifestations of these diseases that are so much to be dreaded. 


\section{THE BRITISH JOURNAL OF VENEREAL DISEASES}

"Now I'm speaking to you as a doctor, and I want you to try to look upon these diseases as I do. To me they present just the same sort of problem as any other infectious disease such as smallpox, diphtheria, measles or typhoid fever. Our business is to get these conditions diagnosed with all speed and treated in such a way that the sufferers will cease to be infectious and will be cured as quickly as possible.

" Ever since the last war free and confidential diagnosis and treatment have been made readily available to everybody. Clinics have been established all over the country where first-class care can be obtained. In country districts certain general practitioners have agreed to give their services free of all charge at their consulting rooms. Any family doctor or any medical officer of health will give the name of the nearest treatment centre. Venereal diseases are among the few diseases we can diagnose with certainty and can cure, in the great majority of cases, with almost equal certainty if only sufferers will seek medical advice in the early stages - unfortunately not all of them do. Furthermore, in recent years the discovery of new drugs has made treatment of one of these diseases not only more speedy but more certain.

"With the cooperation of the public we could reduce the incidence of these diseases enormously - but the public have difficulty in cooperating because of the extraordinary policy of secrecy that has been maintained regarding this particular subject. Young people are only too often ignorant of the very existence of these diseases, and.people of all ages are suffering from their after-effects through ignorance of the early diagnosis and prompt and adequate treatment.

"Well, we've faced up to many difficult situations during this war, so let's face up to this one. It's not so enormous after all. Here are a few figures. In 1931 just over 9,000 cases of syphilis contracted during the year attended the clinics in England and Wales-and the great majority of cases of syphilis find their way to these clinics. In 1939 this figure had fallen to just below 5,000. In 1941 it had risen again to 7,332. The war-time increase has thus been 50 per centseventy per cent if we include all Service infections contracted in this country.

"We've less accurate figures about gonorrhoea because many of the sufferers are treated by private doctors and the disease is not notifiable to the medical officer of health. Unfortunately, too, some victims of gonorrhoea don't seek skilled treatment at all. However, we do know that, roughly speaking, there are about eight new cases of gonorrhoea for each one of syphilis so we can reckon on some 60,000 new cases of gonorrhoea last year, making a total of nearly 70,000 infections from venereal disease among civilians. I think you will agree that while this is a serious problem it isn't by any means too big to handle-out of a total adult population of some thirty millions.

" The increase that has occurred is all the more tragic because of the steady fall in syphilis that had been taking place in the pre-war years. Year by year, right up to the outbreak of war, the disease had been declining. Even now the war-time increase means no more than a setback to the position we had reached in 1932. It's nonsense to suggest that this country has had a bad record of venereal disease. We've good reason to believe, from all the information at our disposal, that we had before the war, and still have, far less than most other countries, and also that the increase we are now experiencing is much lower than in the last war. But because we have had such a good record there is all the more reason why we should try to keep it.

" How are we going to deal with the situation? I'll tell you how we shall never be able to deal with it-or indeed with any other difficult situation-and that is by running away from it, by shutting our eyes to its existence, by refusing to discuss it, or by withholding from young people information regarding its dangers. We have the knowledge and the facilities we need. Early diagnosis and early skilled treatment are available and everyone should be made aware of the prevalence of venereal disease, how it is contracted and how it may be cured. There must be no more secrecy. 


\title{
ASSOCIATED GONORRHOEA and LYMPHOGRANULOMA VENEREUM
}

" The early stages of these diseases often cause little disability and the sufferers put off seeking medical advice because they think the condition is trivial and will clear up by itself. Sometimes they try some sort of quack remedy-although it is illegal to sell such remedies nowadays. This sort of delay and these irregular methods of treatment bring disaster in their train. If sufferers wait till the later stages of the illness have shown themselves-when they can no longer manage without medical help-all hope of cure may have gone.

"We cannot afford-especially at such a time as this-to have a single person off work on account of diseases that are readily diagnosed and amenable to treatment. So let's decide here and now that we shall no longer tolerate this hushhush attitude regarding venereal disease. With the help of an enlightened public opinion we could easily reduce these diseases to insignificant proportions, and I hope you will lend your support to our efforts to rid this country of yet another of its social plagues."

\section{ASSOCIATED GONORRHOEA and LYMPHOGRANULOMA VENEREUM URETHRAL INFECTION IN MALES}

\author{
By WALDEMAR E. COUTTS, M.D.
}

Social Hygiene Department, Public Health Service, Chile, South America

Venereologists during the present decade have shown an increasing interest in lymphogranuloma venereum. Infections associated with syphilis and soft chancre have been reported frequently and studied in great detail. Mixed infections of gonorrhoea and lymphogranuloma venereum have also been recorded, some with a chancre and inguinal adenopathy and a few with urethral penetration of the virus. These are not uncommon owing to the fairly high incidence of the carrier state of lymphogranuloma venereum in women.

The problem of associated gonorrhoea and lymphogranuloma venereum infection has interested me ever since the suggestion by P. L. Gibson (1931) that the virus of lymphogranuloma vemereum might invade the posterior urethra. The association of the infections was seen more frequently before the advent of modern chemotherapy. Nowadays the cases are fewer but nevertheless of considerable importance. I shall refer only to the acute manifestations of cases of simultaneous urethral infection by the virus of lymphogranuloma venereum and the gonococcus.

\section{Forms of simultaneous mixed infection}

J. May (1938) paid special interest to simultaneous conditions of gonorrhoea and lymphogranuloma venereum and considered that an associated gonorrhoealymphogranuloma venereum infection may present itself as (1) a simultaneous infection in which the symptoms of gonorrhoea appear first and three to four weeks later those of lymphogranuloma venereum. (marked oedema of the prepuce, infiltration of the lymphatics of the coronal sulcus or of the dorsum penis and nodular growths in the dorsal lymphatics); (2) a simultaneous infection with a latent primary lymphogranulomatous period and the appearance of syndromes (genital oedemas, genital changes, rectal stricture) years later ; (3) a simultaneous infection with urethritis and lymphogranulomatous chancre; (4) lymphogranuloma-neisserian biotropism.

\section{Clinical course}

In my experience the incubation period of lymphogranuloma venereum is shortened (three to six days) by the simultaneous invasion, and in most cases the symptoms appear early, often at the same time as the discharge begins. There may be oedema of the external urinary meatus and the prepuce, thickening of the 